\title{
BMJ Open Gender differences in faculty rank among academic physicians: a systematic review and meta-analysis
}

Ben Li (D) , ${ }^{1,2}$ Jean Jacob-Brassard, ${ }^{1,2}$ Fahima Dossa (D) , ${ }^{1,3}$ Konrad Salata, ${ }^{1,2}$ Teruko Kishibe, ${ }^{4,5}$ Elisa Greco, ${ }^{1,2}$ Nancy N Baxter, ${ }^{1,5,6}$ Mohammed Al-Omran ${ }^{1,2,5,7}$

To cite: Li B, Jacob-Brassard J, Dossa F, et al. Gender differences in faculty rank among academic physicians: a systematic review and meta-analysis. BMJ Open 2021;11:e050322. doi:10.1136/ bmjopen-2021-050322

- Prepublication history and additional supplemental material for this paper are available online. To view these files, please visit the journal online (http://dx.doi.org/10.1136/ bmjopen-2021-050322)

Presented at Society for Vascular Surgery 2021 Vascular Annual Meeting, San Diego, California, United States; August 18-21, 2021

Received 18 February 2021 Accepted 30 September 2021

\section{Check for updates}

(c) Author(s) (or their employer(s)) 2021. Re-use permitted under CC BY-NC. No commercial re-use. See rights and permissions. Published by BMJ.

For numbered affiliations see end of article.

Correspondence to Dr Mohammed Al-Omran; mohammed.al-omran@ unityhealth.to

\section{ABSTRACT}

Objective Many studies have analysed gender bias in academic medicine; however, no comprehensive synthesis of the literature has been performed. We conducted a pooled analysis of the difference in the proportion of men versus women with full professorship among academic physicians.

Design Systematic review and meta-analysis.

Data sources MEDLINE, Embase, Cochrane Central Register of Controlled Trials, Education Resources Information Center and PsycINFO were searched from inception to 3 July 2020.

Study selection All original studies reporting faculty rank stratified by gender worldwide were included.

Data extraction and synthesis Study screening, data extraction and quality assessment were performed by two independent reviewers, with a third author resolving discrepancies. Meta-analysis was conducted using random-effects models.

Results Our search yielded 5897 articles. 218 studies were included with 991207 academic physician data points. Men were 2.77 times more likely to be full professors (182 271/643 790 men vs $30349 / 251501$ women, OR $2.77,95 \% \mathrm{Cl} 2.57$ to 2.98). Although men practised for longer (median 18 vs 12 years, $p<0.00002$ ), the gender gap remained after pooling seven studies that adjusted for factors including time in practice, specialty, publications, h-index, additional $\mathrm{PhD}$ and institution (adjusted OR 1.83, 95\% Cl 1.04 to 3.20). Meta-regression by data collection year demonstrated improvement over time $(p=0.0011)$; however, subgroup analysis showed that gender disparities remain significant in the 2010-2020 decade (OR 2.63, 95\% Cl 2.48 to 2.80). The gender gap was present across all specialties and both within and outside of North America. Men published more papers (mean difference $17.2,95 \% \mathrm{Cl} 14.7$ to 19.7 ), earned higher salaries (mean difference \$33 256, 95\% Cl \$25 969 to $\$ 40542$ ) and were more likely to be departmental chairs (OR 2.61, 95\% Cl 2.19 to 3.12 ).

Conclusions Gender inequity in academic medicine exists across all specialties, geographical regions and multiple measures of success, including academic rank, publications, salary and leadership. Men are more likely than women to be full professors after controlling for experience, academic productivity and specialty. Although there has been some improvement over time, the gender disparity in faculty rank persists.

PROSPERO registration number CRD42020197414.

\section{Strengths and limitations of this study}

This systematic review and meta-analysis comprehensively synthesises the literature on gender inequity in academic medicine with full professorship as the primary outcome.

- Five major databases were searched including studies globally with no language limitations.

- We analysed trends over time, across specialties, and between geographical regions.

- Both unadjusted and adjusted data were pooled.

- Individual participant-level data were not available; a study-level meta-analysis was conducted.

\section{INTRODUCTION}

Gender equity remains an important issue in academic medicine. In the USA, women make up more than half of medical school graduates $^{1}$ and $37 \%$ of full-time faculty. ${ }^{2}$ However, only $24 \%$ of full professors, ${ }^{3} 18 \%$ of department chairs ${ }^{4}$ and $17 \%$ of deans are women. ${ }^{5}$ Women are under-represented on editorial boards, have fewer publications and receive less research funding. ${ }^{7}$ Due to these inequities, women are more likely to leave academia. ${ }^{8}$ Previous studies have demonstrated the positive impact of healthcare workforce diversity on patient outcomes, costs, and innovation. ${ }^{9}$ Therefore, gender imbalances in academic medicine, particularly in leadership positions, have broad negative implications. ${ }^{10}$

An important indicator of gender inequity in academic medicine is the difference in the proportion of women versus men with full professorship. ${ }^{11}$ The decision to appoint a physician to full professor is usually made by a medical school committee and generally takes into consideration a candidate's clinical and academic contributions. ${ }^{12}$ However, this varies across settings based on institutional values, specialty, and conscious or unconscious bias of promotions committee members. ${ }^{13-15}$ Importantly, several studies 
have demonstrated that women are less likely than men to be full professors even after adjusting for clinical and academic productivity. ${ }^{16-18}$

The current literature on gender bias in academic medicine is limited to single studies that assess one institution, ${ }^{19} 20$ specialty $^{21-24}$ or country. ${ }^{25-29}$ Furthermore, the cross-sectional nature of most analyses precludes an investigation of trends over time. ${ }^{30-32}$ We conducted a systematic review and meta-analysis to calculate a pooled measurement of gender differences in full professorship worldwide and assessed variations across specialties, between geographical regions and over time.

\section{METHODS}

\section{Protocol and registration}

We conducted a systematic review and meta-analysis and reported our findings according to the Preferred Reporting Items for Systematic Reviews and Meta-Analyses (PRISMA) statement guidelines. ${ }^{33}$ Our study protocol (CRD42020197414) was registered with the International Prospective Register of Systematic Reviews. ${ }^{34}$

\section{Information sources and search strategy}

MEDLINE, Embase, Cochrane Central Register of Controlled Trials (CENTRAL), PsycINFO and Education Resources Information Center (ERIC) were searched from inception to 3 July 2020 for studies analysing gender differences in faculty rank among academic physicians. A combination of Medical Subject Heading terms and keywords for gender AND physician AND faculty AND rank were used to maximise sensitivity. Our search did not apply language limitations and Google Translate was used for non-English studies. ${ }^{35}$ The search strategy is detailed in online supplemental eTable 1.

\section{Study selection and data collection}

Title and abstract screening, full-text review, data collection and study quality assessment were conducted by two independent reviewers (BL and JJ-B), with a third author resolving discrepancies (FD). We included all original studies reporting faculty rank stratified by gender among academic physicians. Included articles did not need to be specifically designed to assess gender differences in faculty rank. As long as studies reported the proportion of full professors in a pool of academic physicians for women and men, they were included. This approach allowed us to capture articles broadly and sensitively. Case reports, reviews and studies reporting data on only one gender were excluded. We hand-searched the reference lists of included studies for additional articles.

A standardised form was used to collect data for included studies. Variables obtained were study authors, publication year, geographical region, data source, specialty, data collection year, sample size, outcomes reported, baseline demographics and effect size measurements. Authors were contacted through email for baseline demographics and effect size measurements if they were not reported in the original publication. When studies reported duplicate data (same data source, year of data collection and outcome), the most comprehensive article was included (largest sample size and/or most outcomes reported). In studies reporting data from multiple years, results from the most recent year were included. Study quality was assessed using the Newcastle-Ottawa Scale (NOS) modified for cross-sectional studies. ${ }^{36} 37$

\section{Outcomes}

The primary outcome was the difference in the proportion of female versus male academic physicians with full professorship. An academic physician was defined as a physician with a medical school appointment (eg, instructors and assistant/associate/full professors). ${ }^{38}$ This primary outcome was chosen because full professorship is generally considered the highest academic rank and an important indicator of the overall status of an academic physician. ${ }^{11}$

The secondary outcomes were total publications, h-index, salary, proportion receiving federal research funding and leadership (proportion who are departmental chairs). Total publications, h-index and federal research funding are markers of academic productivity. ${ }^{39}$ Federal research funding was defined as any funding received by academic physicians from a national government. ${ }^{40}$ Salary and departmental chair positions are other indicators of physician status. ${ }^{41} 42$

\section{Statistical analysis}

We calculated a $\kappa$ statistic to assess inter-rater agreement at the title/abstract screening and full-text review stages, with a threshold of $\geq 0.8$ indicating strong agreement. ${ }^{43}$ Baseline covariates for men versus women were compared by calculating median values across included studies and applying unpaired t-test.

We conducted a meta-analysis of the proportion of men versus women with full professorship. Unadjusted estimates were reported as ORs with 95\% CIs. Adjusted estimates were calculated using the inverse variance method and reported as adjusted OR with 95\% CI. ${ }^{44}$ Sensitivity analyses were conducted by excluding low-quality studies (NOS score $\leq 5) .{ }^{45}$ We performed meta-regression and subgroup analysis based on data collection year to assess for trends over time and gender disparities in the modern era. We also conducted subgroup analyses for studies within versus outside of North America, surgical versus non-surgical specialties, and across specialties. For subgroup analysis by specialty, data were included from studies that reported specialty-specific results either as their primary or subgroup analysis. Subgroup differences were analysed by calculating between-subgroup variance as described by Borenstein and Higgins. ${ }^{46}{ }^{47}$ Continuous outcome estimates for publications, h-index and salary were reported as mean differences with $95 \%$ CIs. Monetary values for salary were converted to US dollars using a standardised currency converter. ${ }^{48}$ Heterogeneity was 
quantified using the $\mathrm{I}^{2}$ statistic, and publication bias was assessed using funnel plots.

Meta-analyses were conducted using Review Manager V.5.4.1 (The Cochrane Collaboration, Copenhagen, Denmark) based on random-effects models. ${ }^{49}$ Metaregression was performed using R V.4.0.3 (R Project for Statistical Computing) ${ }^{50}$ with meta $^{51}$ and metaphor ${ }^{52}$ packages. Statistical tests were two-sided with a significance threshold of $\mathrm{p}<0.05$.

\section{Patient and public involvement}

Patients or the public were not involved in the design, conduct, reporting or dissemination plans of our research.

\section{RESULTS}

\section{Study screening and selection}

We identified 8050 articles through our search of MEDLINE $(n=3383)$, Embase $(n=2810)$, PsycINFO $(\mathrm{n}=907)$, ERIC $(\mathrm{n}=633)$ and CENTRAL $(\mathrm{n}=317)$. A total of 5897 articles remained after duplicates were removed, all of which underwent title and abstract screening. A total of 4827 records were excluded and 1070 underwent full-text review. Eight hundred fifty-two studies (852) were excluded, most commonly because there was no relevant outcome $(n=606)$ or no stratification by gender $(\mathrm{n}=115)$, or they contained duplicate data of an included study $(n=54)$. Hand search of reference lists of included studies identified no additional articles. Two hundred eighteen (218) studies were included in the final systematic review and meta-analysis. Inter-rater agreement was strong at title/abstract screening $(\kappa=0.88)$ and full-text review ( $\kappa=0.89)$. Our search results are summarised in the PRISMA study flow diagram in figure 1.

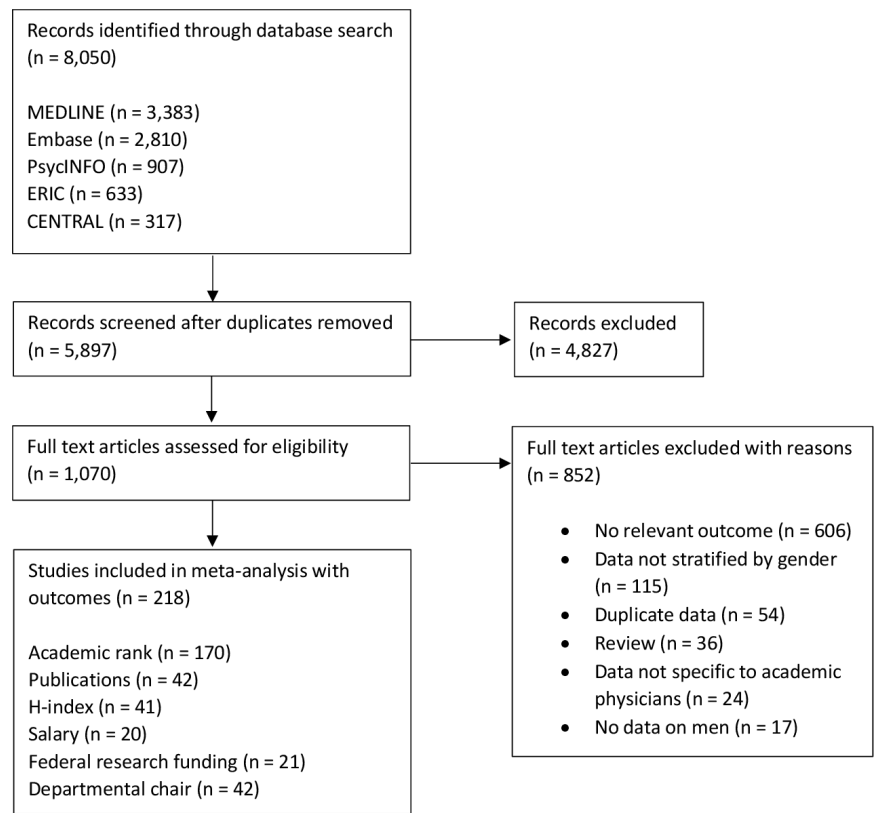

Figure 1 Preferred Reporting Items for Systematic Reviews and Meta-Analyses (PRISMA) study flow diagram.

\section{Study characteristics}

We included 218 cross-sectional studies published between 1979 and 2020. In total, 991207 academic physician data points were included (699 010 men vs 292197 women). The population included instructors and assistant/associate/full professors. One hundred seventy studies reported academic rank (7 adjusted); 42 reported publications (1 adjusted); 41 reported h-index (1 adjusted); 20 reported salary (2 adjusted); 21 reported federal research funding (1 adjusted); and 42 reported departmental chair data (0 adjusted). An increasing number of studies were published in the past decade (2010-2020: 164 studies (75\%) vs before 2010: 54 studies $(25 \%))$. Outcomes were reported on 24 specialties across 16 regions, including countries from Europe, ${ }^{7}$ Asia $^{7}$ and North America. ${ }^{2}$ Data sources included surveys $(\mathrm{n}=89$, $40 \%)$, departmental websites $(n=71,33 \%)$ and faculty databases $(n=58,27 \%)$. The characteristics of included studies are summarised in online supplemental eTable $2 \mathrm{a}$, and the numbers of included studies by country are presented in online supplemental eTable 2b.

\section{Baseline demographic data}

Ninety studies reported baseline demographic data. Median values of covariates across included studies were assessed. Men were older (median age 47.7 vs 43.5, $\mathrm{p}<0.00001$ ) and practised for longer (median 18 vs 12 years, $\mathrm{p}<0.00002)$. Most academic physicians were white (median $74 \%$ (men) and $75 \%$ (women), $\mathrm{p}=0.56$ ). Men were more likely to be married (median $91 \%$ vs $75 \%, \mathrm{p}<0.0002$ ) and have children (median $84 \%$ vs $71 \%, \mathrm{p}<0.0007)$. There were no significant differences in number of hours worked (median 58.0 (men) vs 54.7 (women), $\mathrm{p}=0.056$ ), percentage of time spent on research (median $27.1 \%$ (men) vs $25.2 \%$ (women), $\mathrm{p}=0.80$ ) or proportion of faculty holding an additional PhD (14.8\% (men) vs $14.6 \%$ (women), $\mathrm{p}=0.57)$. Baseline demographic data for included studies are presented in online supplemental eTable 3.

\section{Study quality}

Of the 218 cross-sectional studies, 127 were good quality (NOS score $\geq 8$ ); 57 were fair quality (NOS score $6-7$ ); and 34 were poor quality (NOS score $\leq 5$ ). The most common reason for diminished study quality was poor comparability of cohorts due to inadequate statistical adjustment for confounders, with 131 studies receiving a score of $0 / 2$ and 24 studies receiving a score of $1 / 2$. Another contributor to poor quality was insufficient characterisation of non-respondents in survey-based articles, with 81 studies receiving a score of $0 / 1$. A summary of study quality assessment is presented in online supplemental eTable 4.

\section{Meta-analysis of full professorship}

For full professorship, 170 studies with 895291 academic physician data points (643 790 men vs 251501 women) were included. Meta-analysis demonstrated that men were 2.77 times more likely to be full professors (182 
$271(28.3 \%)$ vs $30349(12.1 \%)$, OR 2.77, 95\% CI 2.57 to $2.98, \mathrm{p}<0.00001, \mathrm{I}^{2}=94 \%$; figure 2 ). Funnel plot showed no evidence of publication bias (online supplemental eFigure 1 ). Sensitivity analysis removing 27 poor-quality studies (NOS score $\leq 5$ ) continued to demonstrate that men were more likely to be full professors (OR 2.81, 95\% CI 2.60 to $3.04, \mathrm{p}<0.00001, \mathrm{I}^{2}=95 \%$; online supplemental eFigure 2).

Seven studies adjusted for potential confounders, including years in practice (Dossani et al, ${ }^{17}$ Gawad et $a l,{ }^{18}$ Jena et $a l,{ }^{16}$ Orhurhu et al,${ }^{53}$ Riaz et al, ${ }^{54}$ Smith et a $\tilde{l}^{5}$ and Sperling et $a l^{56}$ ); specialty (Jena et $a l$ ); publications (Dossani et al, Gawad et al, Jena et al, Riaz et al and Sperling et al); h-index (Dossani et al, Gawad et al, Orhurhu et al, Riaz et al and Sperling et al); additional PhD (Dossani et al, Gawad et al and Sperling et al); and institution (Dossani et al, Jena et al, Orhurhu et al, Riaz et al and Sperling $e t a l$ ). Pooling the adjusted effect estimates comparing 64469 men to 32063 women demonstrated that men were 1.83 times more likely to be full professors (adjusted OR $1.83,95 \%$ CI 1.04 to $3.20, \mathrm{p}=0.03, \mathrm{I}^{2}=91 \%$; figure 3).

To assess trends over time, meta-regression was performed based on data collection year, which demonstrated a reduction in the gender gap between 1979 and 2020 ( $\mathrm{p}=0.0011$, figure 4). Of note, 1979 was the data collection year for the first study on gender differences in faculty rank of academic physicians based on our search. To evaluate gender disparities in the modern era, subgroup analysis was performed by decade (figure 5). Before 2000, men were 3.62 times more likely to be full professors (OR 3.62, 95\% CI 3.27 to 4.01, p $<0.00001$, $\left.\mathrm{I}^{2}=85 \%\right)$. Between 2000 and 2009 , men were 2.85 times more likely to be full professors (OR 2.85, 95\% CI 2.36 to 3.42, $\mathrm{p}<0.00001, \mathrm{I}^{2}=97 \%$ ). Between 2010 and 2020, men were 2.63 times more likely to be full professors (OR 2.63, $95 \%$ CI 2.48 to $2.80, \mathrm{p}<0.00001, \mathrm{I}^{2}=63 \%$ ).

Differences between geographical regions were analysed (online supplemental eFigure 3). Given that the majority of included studies were published in North America (182/218), we compared countries within North America to countries outside of North America. Within North America, men were 2.87 times more likely to be full professors (OR 2.87, 95\% CI 2.65 to 3.10, p<0.00001, $\left.\mathrm{I}^{2}=95 \%\right)$. Outside of North America, men were 2.34 times more likely to be full professors (OR 2.34, 95\% CI 1.80 to $\left.3.04, \mathrm{p}<0.00001, \mathrm{I}^{2}=82 \%\right)$. There was no significant difference between countries in North America versus outside of North America $\left(\chi^{2}=2.12, p=0.15\right)$.

Surgical specialties were compared with non-surgical specialties (online supplemental eFigure 4). For surgical specialties, men were 2.99 times more likely to be full professors (OR 2.99, 95\% CI 2.64 to 3.40, p $<0.00001$, $\left.\mathrm{I}^{2}=72 \%\right)$. For non-surgical specialties, men were 2.72 times more likely to be full professors (OR $2.72,95 \%$ CI 2.48 to $2.98, \mathrm{p}<0.00001, \mathrm{I}^{2}=84 \%$ ). There was no significant difference between surgical and non-surgical specialties $\left(\chi^{2}=1.43, \mathrm{p}=0.23\right)$.
Analysis of individual specialties demonstrated that men were more likely to be full professors across all specialties (online supplemental eFigure 5). The specialty with the smallest gender difference in full professorship was neurosurgery (five studies; OR $2.14,95 \%$ CI 1.30 to $\left.3.52, \mathrm{p}=0.003, \mathrm{I}^{2}=59 \%\right)$. The specialty with the greatest gender difference in full professorship was obstetrics and gynaecology (eight studies; OR 4.52, 95\% CI 3.51 to 5.81, $\left.\mathrm{p}<0.00001, \mathrm{I}^{2}=70 \%\right)$.

\section{Meta-analysis of secondary outcomes}

For total publications, 42 studies comparing 96483 men to 47910 women were included. Over their careers, men published 17.20 more papers (mean difference 17.20, $95 \%$ CI 14.68 to $19.72, \mathrm{p}<0.00001, \mathrm{I}^{2}=99 \%$; online supplemental eFigure 6). Funnel plot demonstrated publication bias skewed towards a higher mean difference (online supplemental eFigure 7). Sensitivity analysis removing five poor-quality studies continued to show that men published more papers (mean difference 17.66, 95\% CI 14.97 to $20.35, \mathrm{p}<0.00001, \mathrm{I}^{2}=99 \%$; online supplemental eFigure 8). One study demonstrated that women continued to have fewer publications after adjusting for career duration (adjusted relative rate $0.46,95 \%$ CI 0.39 to 0.55$).^{57}$

For h-index, 41 studies comparing 29923 men to 12 286 women were included. Men had a higher h-index than women (mean difference 5.97, 95\% CI 4.77 to 7.16 , $\mathrm{p}<0.00001, \mathrm{I}^{2}=98 \%$; online supplemental eFigure 9). Funnel plot demonstrated no evidence of publication bias (online supplemental eFigure 10). Sensitivity analysis removing one poor-quality study continued to show that men had a higher h-index (mean difference 5.98, $95 \%$ CI 4.77 to $7.19, \mathrm{p}<0.00001, \mathrm{I}^{2}=98 \%$; online supplemental eFigure 11). One study demonstrated that women continued to have a lower h-index after adjusting for career duration (adjusted relative rate $0.62,95 \%$ CI 0.54 to 0.72$).^{57}$

For federal research funding, 21 studies comparing 87205 men to 39638 women were included. Men were 1.71 times more likely to hold a federal research grant (OR $1.71,95 \%$ CI 1.41 to 2.08 , $\mathrm{p}<0.00001, \mathrm{I}^{2}=88 \%$; online supplemental eFigure 12). Funnel plot demonstrated evidence of publication bias skewed towards a higher OR (online supplemental eFigure 13). Sensitivity analysis removing two poor-quality studies continued to show that men were more likely to hold a federal research grant (OR $1.55,95 \%$ CI 1.30 to $1.84, \mathrm{p}<0.00001, \mathrm{I}^{2}=75 \%$; online supplemental eFigure 14). One study demonstrated no difference in the proportion of men versus women receiving federal research funding after controlling for time in practice, additional degrees, publications and h-index (adjusted OR 1.23, 95\% CI 0.79 to 1.92 ). ${ }^{56}$

For salary, 20 studies comparing 15155 men to 7837 women were included. Men's salary was $\$ 32520$ higher (mean difference $\$ 32520,95 \%$ CI $\$ 25790$ to $\$ 39260$, $\mathrm{p}<0.00001, \mathrm{I}^{2}=94 \%$; online supplemental eFigure 15 ). Funnel plot showed evidence of publication bias skewed 


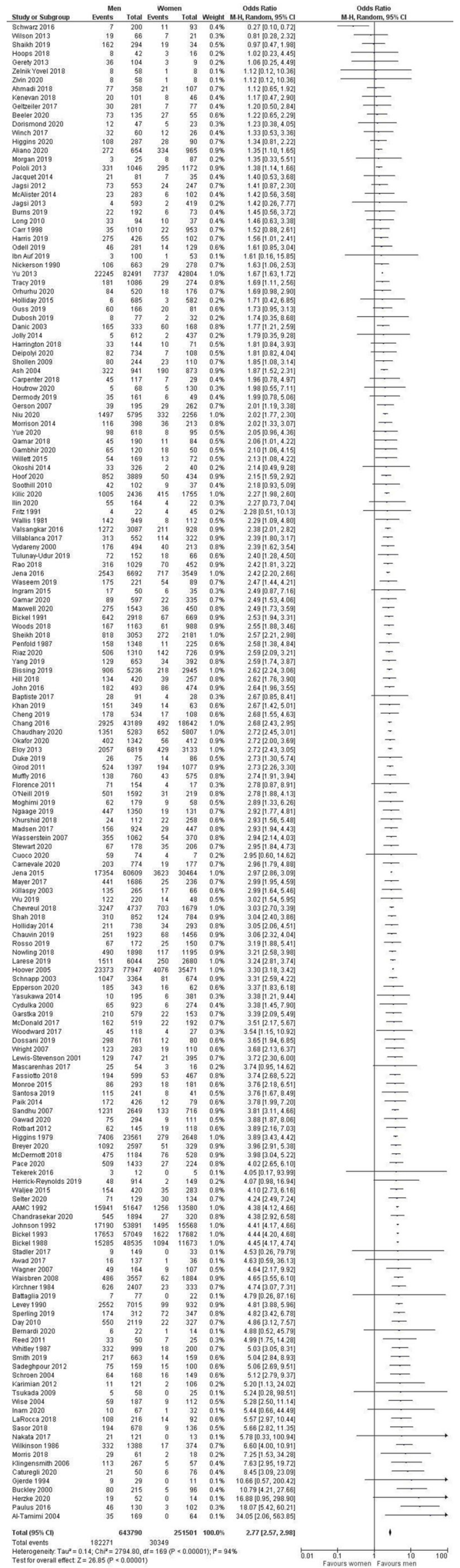

Figure 2 Forest plot of full professorship for men versus women. M-H, Mantel-Haenszel; Random, random effects model. 


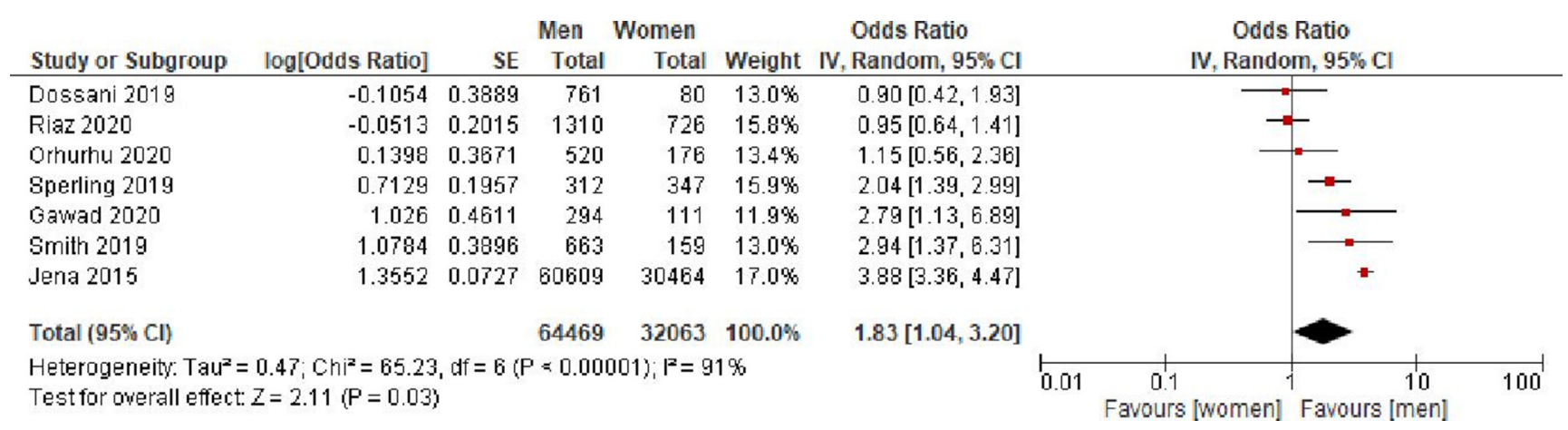

Figure 3 Forest plot of full professorship adjusted for years in practice (Dossani, Gawad, Jena, Orhurhu, Riaz, Smith and Sperling); specialty (Jena); publications (Dossani, Gawad, Jena, Riaz and Sperling); h-index (Dossani, Gawad, Orhurhu, Riaz and Sperling); additional PhD (Dossani, Gawad and Sperling); and institution (Dossani, Jena, Orhurhu, Riaz and Sperling). IV, inverse variance; Random, random effects; SE, standard error; Total, sample size.

towards a higher mean difference (online supplemental eFigure 16). Sensitivity analysis removing one poorquality study continued to show that men received a higher salary than women (mean difference $\$ 34930$, $95 \%$ CI $\$ 25920$ to $\$ 43950, \mathrm{p}<0.00001, \mathrm{I}^{2}=95 \%$; online supplemental eFigure 17). Two studies reported adjusted estimates for salary. Jena et at ${ }^{41}$ demonstrated that men earned more after controlling for time in practice, research funding, publications and clinical trial participation (adjusted absolute difference $\$ 19$ 878, $95 \%$ CI $\$ 15$ 261 to $\$ 24495) .{ }^{41}$ Gambhir et $a \bar{l}^{8}$ also showed that men received a higher salary after adjusting for academic rank and specialty (adjusted absolute difference $\$ 45904,95 \%$ CI $\$ 13264$ to $\$ 103137) .^{58}$

For leadership, 42 studies comparing 48613 men to 26958 women were included. Men were 2.61 times more likely to be a departmental chair (OR 2.61, 95\% CI 2.19 to $3.12, \mathrm{p}<0.00001, \mathrm{I}^{2}=55 \%$; online supplemental eFigure 18). Funnel plot demonstrated no evidence of publication bias (online supplemental eFigure 19). Sensitivity analysis removing six poor-quality studies continued to show that men were more likely to be departmental chairs (OR 2.60, 95\% CI 2.16 to 3.13, $\mathrm{p}<0.00001, \mathrm{I}^{2}=59 \%$; online supplemental eFigure 20). No studies reported adjusted estimates for this outcome.

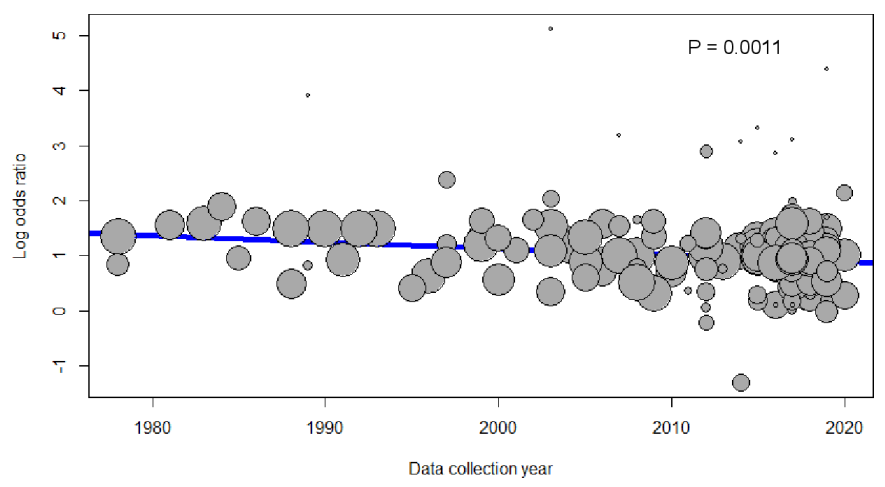

Figure 4 Meta-regression of full professorship based on data collection year. Each circle represents a unique study; the size of the circle indicates weight; and the blue line shows the trend over time. The $Y$ axis represents the log OR of the proportion of men versus women with full professorship.
A meta-analysis of adjusted estimates for secondary outcomes was not performed due to a paucity of studies.

\section{DISCUSSION}

\section{Summary of findings}

This systematic review and meta-analysis of 218 studies including 991207 academic physician data points demonstrated that men were 2.77 times more likely to be full professors than women. This was consistent across specialties and geographical regions. There has been some improvement over time, but in the 2010-2020 decade, men were 2.63 times more likely to be full professors. Although men practised 6 years longer than women, men continued to be 1.83 times more likely to be full professors after pooling results from seven studies that controlled for number of years in practice. Furthermore, men published 17.2 more papers, had an h-index that was 5.97 higher, received a salary that was $\$ 32520$ greater, and were 2.61 and 1.71 times more likely to be departmental chairs and to receive federal research funding, respectively. Among single studies, men continued to have more publications, higher h-indices and greater salaries after adjusting for factors including time in practice and specialty. ${ }^{415758}$

\section{Comparison to existing literature}

This was the first systematic review and meta-analysis of gender differences in faculty rank among academic physicians. Our findings are consistent with most of the single studies in the literature demonstrating significant gender disparities in academic rank. Specifically, our pooled analysis of 24 specialties across 16 countries confirmed that the gender disparity in full professorship is pervasive across specialties globally.

Jena $e t a l^{16}$ performed the largest single study on this topic, analysing 91073 US academic physicians. They showed that $28.6 \%$ of men were full professors compared with $11.9 \%$ of women, for an absolute difference of $16.7 \%{ }^{16}$ In their study, men were older, more likely to hold federal research grants and published more papers. However, after adjusting for experience, research 


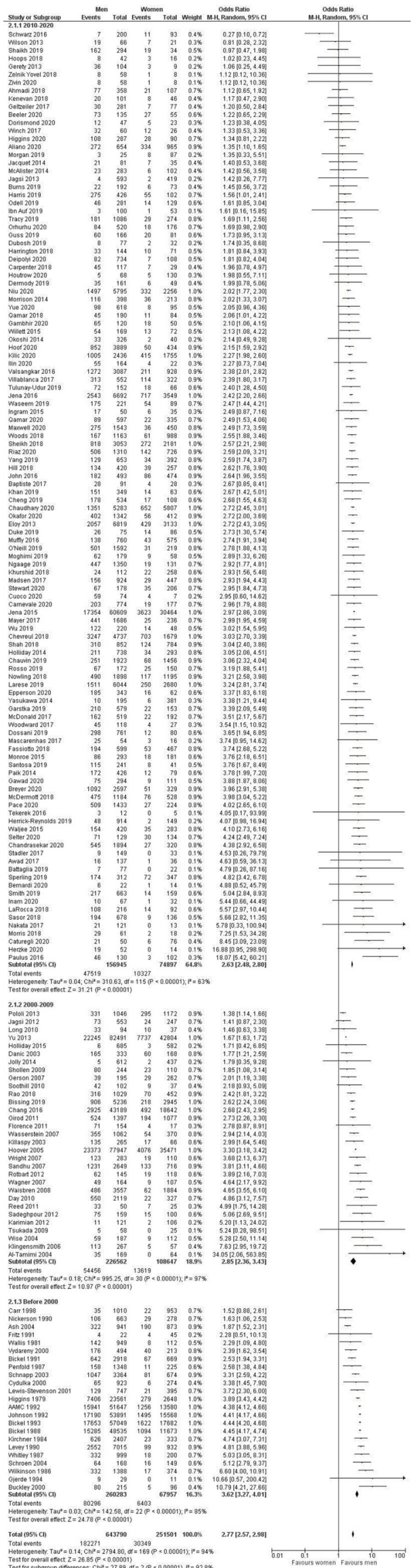

Figure 5 Subgroup analysis of full professorship by decade based on data collection year (before 2000, 2000-2009, 20102020). M-H, Mantel-Haenszel; Random, random effects model. 
productivity and specialty, women continued to be less likely than men to be full professors, with an absolute difference of $4 \% .{ }^{16}$ We demonstrated similar findings across specialties, over time and between geographical regions in a larger pooled cohort.

\section{Explanation of findings}

In our study, men practised for 6 years longer than women, which may have contributed to men being 2.77 times more likely to be full professors. However, after pooling seven studies that adjusted for number of years in practice, men continued to be 1.83 times more likely to attain full professorship. Therefore, differences in career duration do not fully explain the gender gap. This is consistent with previous studies showing that men were more likely to hold higher academic positions after adjusting for time in practice. ${ }^{171853}$

Several studies have explored reasons for gender inequity in academic medicine. In a survey of 4285 US paediatricians, women were less likely to report that they received adequate mentorship. ${ }^{21}$ Other studies have demonstrated gender-based discrimination, ${ }^{59}$ unequal allocation of institutional resources ${ }^{60}$ and lack of promotion tracks for women who take time off for childcare. ${ }^{61}$ In addition to inequity at work, inequity at home may also influence progress in academic medicine. Jolly and colleagues ${ }^{62}$ surveyed 1049 US clinician-scientists and found that women spent 8.5 more hours/week on household activities than men. ${ }^{62}$ Due to these inequities, women are more likely to leave academia. ${ }^{63}$ These reasons could explain the gender differences in academic rank, research productivity, salary and leadership.

Notably, our study demonstrated that a similar gender gap in full professorship exists for countries within and outside of North America. Despite geographical and cultural differences, gender inequity is a global phenomenon. This systemic problem exists not only in healthcare but also in education, ${ }^{64}$ income $^{65}$ and political power. ${ }^{66}$

Our analysis showed that men were more likely than women to be full professors across every specialty. Interestingly, $39 \%$ of faculty in obstetrics and gynaecology were women, yet men were four times more likely to be full professors. Rayburn and colleagues ${ }^{67}$ analysed US faculty in obstetrics and gynaecology and found an increase in the proportion of female entry-level faculty, but they were primarily in the non-tenure track. ${ }^{67}$ They showed that promotion rates dropped from $35 \%$ in $1980-1989$ to $26 \%$ in 2000-2009. ${ }^{67}$ Therefore, in specialties where there is an increasing number of women entering but few opportunities for advancement, the gender gap may be widening.

We showed minimal improvement in gender disparities over time, with men being 2.63 times more likely to be full professors in 2010-2020. As demonstrated in the example of obstetrics and gynaecology, waiting for more women to enter the academic pipeline will be insufficient to close the gender gap. One method of actively improving gender equity is implementing programmes that directly support women. For example, Stanford University's School of
Medicine established the Office of Diversity and Leadership in 2004. ${ }^{68}$ They developed research awards, mentorship programmes and networking events for women. ${ }^{68}$ Over the next 6 years, the number of female full professors increased from 52 to $91 .^{68}$ This rise was $60 \%$ greater than the national promotion rate to full professor for women. ${ }^{68}$ Similar career development programmes at Johns Hopkins University ${ }^{69}$ and the University of Michigan $^{70}$ have demonstrated benefits to female academic physicians. In Europe, many medical schools have instituted Athena Scientific Women's Academic Network action plans, which are a set of multilevel interventions that address structural, cultural and institutional factors that create barriers for women. ${ }^{71}$ This broadbased strategy has significantly improved female representation in leadership positions. ${ }^{72}$ However, Carr and colleagues ${ }^{73}$ demonstrated that many institutions do not have programmes to support gender equity ${ }^{73}$ This may explain the ongoing gender gap, which can be further closed by expanding interventions that support women to a national and global scale.

\section{Limitations}

This study was limited by high heterogeneity in most of the analyses conducted. This was expected as we pooled effect estimates across multiple specialties, data sources, and countries. Subgroup analysis by specialty demonstrated a reduction in heterogeneity. Therefore, data variability across specialties may be a source of heterogeneity in our study.

Funnel plots for secondary outcomes including publications, federal research funding, and salary demonstrated evidence of publication bias, which may have contributed to overestimation of the gender gap. However, there was no evidence of publication bias for the primary outcome of academic rank.

There may be selection bias due to the inclusion of cross-sectional studies that did not statistically adjust for confounding. However, pooling of studies that controlled for potential confounders demonstrated that men continued to be more likely than women to be full professors. Sensitivity analysis was also conducted to remove poor-quality studies, which did not have a significant impact on the pooled estimate for any outcome.

We intended to reduce the risk of counting a study participant more than once by including only the most comprehensive article (largest sample size and/or most outcomes reported) when multiple studies reported duplicate data (same data source, year of data collection, and outcome). However, this risk could not be completely mitigated without participant-level data, which was not available in our study-level meta-analysis.

In our cohort, we did not have information on the academic ranks of all the participants (eg, instructors and assistant/associate professors) as many studies only reported the number of full professors out of a pool of academic physicians. We recommend that future studies 
on this topic report the academic ranks of all their participants.

\section{CONCLUSIONS}

This systematic review and meta-analysis provides a comprehensive synthesis of the literature on gender differences in faculty rank among academic physicians. We demonstrated that men were more likely to be full professors than women after adjusting for experience, academic productivity, and specialty. The gender gap exists across all specialties and geographical regions. Gender inequity persists even in the most contemporaneous studies, indicating that gender disparities in faculty rank will remain unless actively addressed. Greater efforts are needed to support women in academic medicine.

\section{Author affiliations}

${ }^{1}$ Department of Surgery, University of Toronto, Toronto, Ontario, Canada

${ }^{2}$ Division of Vascular Surgery, St. Michael's Hospital, Unity Health Toronto, Toronto, Ontario, Canada

${ }^{3}$ Division of General Surgery, St. Michael's Hospital, Unity Health Toronto, Toronto, Ontario, Canada

${ }^{4}$ Health Sciences Library, St. Michael's Hospital, Unity Health Toronto, Toronto, Ontario, Canada

${ }^{5}$ Li Ka Shing Knowledge Institute, St. Michael's Hospital, Unity Health Toronto, Toronto, Ontario, Canada

${ }^{6}$ Melbourne School of Population and Global Health, University of Melbourne, Melbourne, Victoria, Australia

${ }^{7}$ Department of Surgery, King Saud University, Riyadh, Kingdom of Saudi Arabia

Contributors BL, JJ-B, FD, KS, TK, EG, NNB, and MAO conceived the study. TK and $B L$ developed the database search. BL, JJ-B and FD screened citations for inclusion, performed risk of bias analysis and extracted the data. BL performed the statistical analysis. BL drafted the manuscript. BL and MA-0 obtained funding. NNB and MA- 0 provided supervision. The study guarantor is $\mathrm{BL}$, who had full access to the data and takes responsibility for the integrity of data collection and accuracy of the data analysis. All authors were involved in designing the study, interpreting the data and critical revision of the manuscript for important intellectual content; reviewed the final manuscript and agreed to be accountable for all aspects of the work; and approved the final manuscript for submission. The corresponding author attests that all listed authors meet authorship criteria, and no others meeting the criteria have been omitted.

Funding This study was funded by the Canadian Society for Vascular Surgery National Student Research Award for Ben Li, grant/award number (2019 CSVS NSRA).

Competing interests BL had financial support from the Canadian Society for Vascular Surgery National Student Research Award for the submitted work.

Patient and public involvement statement Patients or the public were not involved in the design, conduct, reporting, or dissemination plans of our research.

Patient consent for publication Not applicable.

Ethics approval This systematic review and meta-analysis was based on published data. The authors did not access any information that could lead to identification of a specific patient. Therefore, ethics approval was not required.

Provenance and peer review Not commissioned; externally peer reviewed.

Data availability statement Data are available upon reasonable request. All data relevant to the study are included in the article or uploaded as supplementary information.

Supplemental material This content has been supplied by the author(s). It has not been vetted by BMJ Publishing Group Limited (BMJ) and may not have been peer-reviewed. Any opinions or recommendations discussed are solely those of the author(s) and are not endorsed by BMJ. BMJ disclaims all liability and responsibility arising from any reliance placed on the content. Where the content includes any translated material, BMJ does not warrant the accuracy and reliability of the translations (including but not limited to local regulations, clinical guidelines, terminology, drug names and drug dosages), and is not responsible for any error and/or omissions arising from translation and adaptation or otherwise.

Open access This is an open access article distributed in accordance with the Creative Commons Attribution Non Commercial (CC BY-NC 4.0) license, which permits others to distribute, remix, adapt, build upon this work non-commercially, and license their derivative works on different terms, provided the original work is properly cited, appropriate credit is given, any changes made indicated, and the use is non-commercial. See: http://creativecommons.org/licenses/by-nc/4.0/.

\section{ORCID iDs}

Ben Li http://orcid.org/0000-0002-7191-1034

Fahima Dossa http://orcid.org/0000-0002-4670-7445

\section{REFERENCES}

1 Association of American Medical Colleges (AAMC). FACTS: Applicants, Matriculants, Enrollment, Graduates, MD/PhD, and Residency Applicants Data [Internet], 2018. Available: https://www. aamc.org/data/facts/ [Accessed 23 Dec 2018].

2 Association of American Medical Colleges (AAMC). The State of Women in Academic Medicine: The Pipeline and Pathways to Leadership, 2015-16 [Internet], 2016. Available: https://www.aamc. org/members/gwims/statistics/ [Accessed 23 Dec 2018].

3 Association of American Medical Colleges (AAMC). U.S. Medical School Faculty by Sex and Rank, 2017 [Internet], 2017. Available: https://www.aamc.org/download/486130/data/17table9.pdf [Accessed 23 Dec 2018].

4 American Association of Medical Colleges (AAMC). Department Chairs by Department, Sex, and Race/Ethnicity, 2017 [Internet], 2017. Available: https://www.aamc.org/download/486590/data/ supplementaltablec.pdf [Accessed 23 Dec 2018].

5 American Association of Medical Colleges (AAMC). U.S. Medical School Dean Trends by Dean Type and Sex, December 31 Snaphsots [Internet], 2017. Available: https://www.aamc.org/download/486596/ data/supplementaltablef.pdf [Accessed 23 Dec 2018].

6 Head MG, Fitchett JR, Cooke MK, et al. Differences in research funding for women scientists: a systematic comparison of UK investments in global infectious disease research during 1997-2010. BMJ Open . 2013;3:e003362.

7 Filardo G, da Graca B, Sass DM, et al. Trends and comparison of female first authorship in high impact medical journals: observational study (1994-2014). BMJ 2016;352:i847.

8 Carr PL, Gunn CM, Kaplan SA, et al. Inadequate progress for women in academic medicine: findings from the National faculty study. $J$ Womens Health 2015;24:190-9.

9 Gomez LE, Bernet P. Diversity improves performance and outcomes. J Natl Med Assoc 2019;111:383-92.

10 Hay K, McDougal L, Percival V, et al. Disrupting gender norms in health systems: making the case for change. Lancet 2019;393:2535-49.

11 Varpio L, Harvey E, Jaarsma D, et al. Attaining full Professor: women's and men's experiences in medical education. Med Educ 2021;55:582-94.

12 Mabrouk PA. Promotion from associate to full Professor. Anal Bioanal Chem 2007;388:987-91.

13 Papaconstantinou HT, Lairmore TC. Academic appointment and the process of promotion and tenure. Clin Colon Rectal Surg 2006;19:143-7.

14 Smith SB, Hollerbach A, Donato AS, et al. Streamlining appointment, promotion, and Tenure procedures to promote early-career faculty success. J Prof Nurs 2016;32:334-41.

15 Cheng TW, Farber A, Rajani RR, et al. National criteria for academic appointment in vascular surgery. J Vasc Surg 2019;69:1559-65.

16 Jena AB, Khullar D, Ho O, et al. Sex differences in academic RANK in US medical schools in 2014. JAMA 2015;314:1149.

17 Dossani RH, Terrell D, Kosty JA, et al. Gender disparities in academic RANK achievement in neurosurgery: a critical assessment. $J$ Neurosurg 2019;133:1922-7.

18 Gawad N, Tran A, Martel AB, et al. Gender and academic promotion of Canadian general surgeons: a cross-sectional study. CMAJ Open 2020;8:E34-40.

19 Nickerson KG, Bennett NM, Estes D. The status of women at one academic medical center. breaking through the glass ceiling. JAMA 1990;264:1813-7.

20 Reed DA, Enders F, Lindor R, et al. Gender differences in academic productivity and leadership appointments of physicians throughout academic careers. Acad Med 2011;86:43-7. 
21 Kaplan SH, Sullivan LM, Dukes KA, et al. Sex differences in academic advancement - results of a national study of pediatricians. N Engl J Med 1996;335:1282-90.

22 Kapoor N, Blumenthal DM, Smith SE, et al. Gender differences in academic rank of radiologists in U.S. medical schools. Radiology 2017;283:140-7.

23 Pashkova AA, Svider PF, Chang CY, et al. Gender disparity among US anaesthesiologists: are women underrepresented in academic ranks and scholarly productivity? Acta Anaesthesio/ Scand 2013;57:1058-64.

24 Mayer EN, Lenherr SM, Hanson HA, et al. Gender differences in publication productivity among academic Urologists in the United States. Urology 2017;103:39-46.

25 Tesch BJ, Wood HM, Helwig AL, et al. Promotion of women physicians in academic medicine. glass ceiling or sticky floor? JAMA 1995;273:1022-5.

26 Carr PL, Friedman RH, Moskowitz MA, et al. Comparing the status of women and men in academic medicine. Ann Intern Med 1993;119:908-13.

27 Nonnemaker L. Women physicians in academic medicine new insights from cohort studies. N Engl J Med Overseas Ed 2000;342:399-405.

28 Selected Higher Education Statistics - 2018 Staff data [Internet]. Australian Government: Department of Education and Training, 2018. Available: https://www.education.gov.au/selected-higher-educationstatistics-2018-staff-data [Accessed 12 Jan 2019].

29 Pritchard R. Gender inequality in British and German universities. Compare 2007;37:651-69.

30 Sugiura-Ogasawara M, Suzuki S, Kitazawa M, et al. Career satisfaction level, mental distress, and gender differences in working conditions among Japanese obstetricians and gynecologists. $J$ Obstet Gynaecol Res [Internet] 2012;38:550-8.

31 Tomei KL, Nahass MM, Husain Q, et al. A gender-based comparison of academic RANK and scholarly productivity in academic neurological surgery. J Clin Neurosci 2014;21:1102-5.

32 Nielsen MW. Scandinavian approaches to gender equality in academia: a comparative study. Scandinavian Journal of Educational Research 2017:61:295-318.

33 Moher D, Liberati A, Tetzlaff J, et al. Preferred reporting items for systematic reviews and meta-analyses: the PRISMA statement. PLoS Med 2009;6:e1000097.

34 National Institute for Health Research (NHS). PROSPERO: International prospective register of systematic reviews [Internet] 2018. Available: https://www.crd.york.ac.uk/prospero/

35 Google Translate [Internet]. Available: https://translate.google.ca/ [Accessed 13 Dec 2020].

36 Wells G, Shea B, O'Connell D. The Newcastle-Ottawa Scale (NOS) for assessing the quality of nonrandomised studies in meta-analyses [Internet. The Ottawa Hospital Research Institute, 2018. http://www. ohri.ca/programs/clinical_epidemiology/oxford.asp

37 Modesti PA, Reboldi G, Cappuccio FP, et al. Panethnic differences in blood pressure in Europe: a systematic review and meta-analysis. PLoS One 2016;11:e0147601.

38 Block SM, Sonnino RE, Bellini L. Defining "faculty" in academic medicine: responding to the challenges of a changing environment. Acad Med 2015:90:279-82.

39 Carpenter CR, Cone DC, Sarli CC. Using publication metrics to highlight academic productivity and research impact. Acad Emerg Med 2014:21:1160-72.

40 Smits PA, Denis J-L. How research funding agencies support science integration into policy and practice: an international overview. Implement Sci 2014:9:28.

41 Jena AB, Olenski AR, Blumenthal DM. Sex differences in physician salary in US public medical schools. JAMA Intern Med 2016;176:1294-304.

42 Salazar DH, Herndon JH, Vail TP, et al. The academic chair: achieving success in a rapidly evolving health-care environment: AOA critical issues. J Bone Joint Surg Am 2018;100:e133.

43 McHugh ML. Interrater reliability: the kappa statistic. Biochem Med 2012;22:276-82

44 Higgins J, Green S. 7.7.7.1 Effect estimates and generic inverse variance. In: Cochrane Handbook for Systematic Reviews of Interventions [Internet], 2020. Available: https://handbook-5-1. cochrane.org/chapter_7/7_7_7_1_effect_estimates_and_generic_ inverse variance.htm [Accessed 01 Jan 2021].

45 Luchini C, Stubbs B, Solmi M, et al. Assessing the quality of studies in meta-analyses: advantages and limitations of the Newcastle Ottawa scale. World J Metaanal 2017:5:80.

46 Borenstein M, Higgins JPT. Meta-Analysis and subgroups. Prev Sci 2013;14:134-43.

47 Higgins J, Green S. 9.6.3.1 Is the effect different in different subgroups? In: Cochrane Handbook for Systematic Reviews of
Interventions [Internet], 2020. Available: https://handbook-5-1. cochrane.org/chapter_9/9_6_3_1_is_the_effect_different_in_different subgroups.htm [Accessed 01 Jan 2021].

48 Currency Converter - Foreign Exchange Rates Calculator |Xe [Internet]. Available: https://www.xe.com/currencyconverter/ [Accessed 02 Aug 2021].

49 RevMan | Cochrane Review Manager [Internet]. Available: https:// training.cochrane.org/online-learning/core-software-cochranereviews/revman [Accessed 02 Aug 2021].

50 R Development Core Team. The R Project for Statistical Computing [Internet], 2020. Available: https://www.r-project.org/ [Accessed 01 Jan 2021].

51 Schwarzer G. Meta: an R package for meta-analysis. $R$ News 2007;7:40-5.

52 Viechtbauer W. Conducting Meta-Analyses in $R$ with the metafor Package. J Stat Softw 2010;36:1-48.

53 Orhurhu MS, Orhurhu V, Salisu B, et al. Factors associated with academic RANK among chronic pain medicine faculty in the USA. Reg Anesth Pain Med 2020;45:589-96.

54 Riaz IB, Siddiqi R, Zahid U, et al. Gender differences in faculty RANK and leadership positions among Hematologists and oncologists in the United States. JCO Oncol Pract 2020;16:e507-16.

55 Smith BT, Egro FM, Murphy CP, et al. Change is happening: an evaluation of gender disparities in academic plastic surgery. Plast Reconstr Surg 2019;144:1001-9.

56 Sperling JD, Shulman R, Blat C, et al. Gender differences in academic RANK and NIH funding among academic MaternalFetal medicine physicians in the United States. Am J Perinatol 2019;36:443-8.

57 Chauvin S, Mulsant BH, Sockalingam S, et al. Gender differences in research productivity among academic psychiatrists in Canada. Can J Psychiatry 2019;64:415-22.

58 Gambhir S, Daly SC, Elfenbein D, et al. The effect of transparency on the gender-based compensation gap in surgical disciplines within a large academic healthcare system. Surg Endosc 2021;35:2607-12.

59 Yedidia MJ, Bickel J. Why Aren't there more women leaders in academic medicine? the views of clinical department chairs. Academic Medicine 2001;76:453-65.

60 Holliday E, Griffith KA, De Castro R, et al. Gender differences in resources and negotiation among highly motivated physicianscientists. J Gen Intern Med 2015;30:401-7.

61 Bunton SA, Mallon WT. The continued evolution of faculty appointment and tenure policies at U.S. medical schools. Acad Med 2007;82:281-9.

62 Jolly S, Griffith KA, DeCastro R, et al. Gender differences in time spent on parenting and domestic responsibilities by high-achieving young physician-researchers. Ann Intern Med 2014;160:344353-53.

63 Cropsey KL, Masho SW, Shiang R, et al. Why do faculty leave? Reasons for attrition of women and minority faculty from a medical school: four-year results. J Womens Health 2008;17:1111-8.

64 Goesling B, Baker DP. Three faces of international inequality. Res Soc Stratif Mobil 2008;26:183-98.

65 Sala-i-Martin X. The World Distribution of Income: Falling Poverty and Convergence, Period. Q J Econ 2006;121:351-97.

66 Kenworthy L, Malami M. Gender inequality in political representation: a worldwide comparative analysis. Social Forces 1999;78:235.

67 Rayburn WF, Schrader RM, Fullilove AM, et al. Promotion rates for assistant and associate professors in obstetrics and gynecology. Obstet Gynecol 2012;119:1023-9.

68 Valantine HA, Grewal D, Ku MC, et al. The gender gap in academic medicine: comparing results from a multifaceted intervention for Stanford faculty to peer and national cohorts. Acad Med 2014;89:904-11.

69 Fried LP, Francomano CA, MacDonald SM, et al. Career development for women in academic medicine: multiple interventions in a department of medicine. JAMA 1996;276:898.

70 Sheridan JT, Fine E, Pribbenow CM, et al. Searching for excellence \& diversity: increasing the hiring of women faculty at one academic medical center. Acad Med 2010;85:999-1007.

71 Kalpazidou Schmidt E, Ovseiko PV, Henderson LR, et al. Understanding the Athena Swan Award scheme for gender equality as a complex social intervention in a complex system: analysis of silver Award action plans in a comparative European perspective. Health Res Policy Syst 2020;18:19.

72 Xiao Y, Pinkney E, Au TKF, et al. Athena Swan and gender diversity: a UK-based retrospective cohort study. BMJ Open 2020;10:e032915.

73 Carr PL, Gunn C, Raj A, et al. Recruitment, promotion, and retention of women in academic medicine: how institutions are addressing gender disparities. Womens Health Issues 2017;27:374-81. 